\title{
Analysis of Circulation Competitiveness of Yunnan Tobacco Enterprise in China
}

\author{
Shen Shen* \\ Economic Department of Teaching and Research \\ Party School of the Yunnan Provincial Committee of C.P.C \\ $\&$ School of Economics \\ Yunnan University of Finance and Economics \\ Kunming, China \\ leon198633@sina.com
}

\author{
Yan Hui \\ School of Economics \\ Yunnan University of Finance and Economics \\ Kunming, China \\ yanhui4779@163.com
}

\begin{abstract}
With the development of supply side structural reforms, circulation of tobacco products is controlled by strong administrative intervention and inhibited by the serious local protectionism under the national monopoly system. In this paper, it does empirical research by principal component analysis and partial least squares method based on the data of $X$ tobacco enterprise in Yunnan province in order to analyze the relevant factors affecting its circulation competitiveness. It finds that the human capital and research have significant influence and restricted by internal structure of capital and external environment. Therefore, the purpose of this paper is to enhance the circulation compe titiveness of tobacco enterprise, re lieve local protectionism, and achieve effective circulation of tobacco products based on limited regulation. In addition, it provides references for the improvement of other industries' circulation efficiency, which is also beneficial to the improvement of circulation competitiveness for the whole industry.
\end{abstract}

Keywords-Tobacco Enterprise; Circulation Competitiveness; Principal Component Analysis; Partial Least Squares

\section{RESEARCH BACKGROUND}

In regard to the 19th National Congress reports, General Secretary $\mathrm{Xi}$ re-emphasized the structural reforms on the supply side. However, China has been carrying out the national tobacco monopoly system, which strictly controls the circulation and the sales of tobacco products. It will inevitably affect the circulation competitiveness of tobacco enterprise. After joining the WTO and signing the Framework Convention on Tobacco Control, the tobacco products from worldwide will enter into the Chinese tobacco market. The domestic tobacco enterprises are also facing the requirement of controlling the quantity of tobacco products and the improvement of their quality. It also will join the competition that challenging the global tobacco market. In addition, due to local finance's reliance on tobacco taxes which is mainly from local tobacco enterprises, serious local protectionism does exist. In fact, Tobacco Monopoly Bureau (company) is entirely responsible for China's tobacco circulation. Although the bureau controls huge profits, it lacks incentive factors in some respect due to the administrative centralization, resulting in a relatively weak circulation competitiveness. In terms of circulation, there is a big gap between the local tobacco

* Corresponding author. This paper is funded by "Research on Farmers' Producing Behaviors under the Regulation of Yunnan Tobacco” (2017FD125) \& "Research on Circulation Competitiveness of Yunnan Tobacco Enterprise" (2016D01). enterprises and the multinational tobacco companies after the opening of the domestic tobacco consumption market. Nowadays, there are few researches on the circulation competitiveness in China and the research on circulation competitiveness of tobacco enterprise is rather limited. The research in this paper will make up for this deficiency and further improve the empirical research methods of circulation competitiveness. Due to the characteristics of tobacco products, samples obtained by investigation and statistical yearbook are fewer. In addition, there is multicollinearity among influence factors. Therefore, based on the investigation of $\mathrm{X}$ tobacco company in Yunnan Province and data of relevant statistical yearbook, this paper chooses the principal component analysis and partial least square method to study the influencing factors of the circulation competitiveness of tobacco enterprises. This paper aims to alleviate the impact of tobacco circulation regulations, continuously promote the circulation competitiveness of China's tobacco enterprises, as well as stimulate the vitality of the tobacco product market so that it can fully and timely meet the requirements of tobacco consumers while competing with international tobacco brands. The research on the circulation competitiveness of tobacco enterprises also provides reference for other industries, especially for areas with serious administrative intervention, and ultimately promotes the overall improvement of China's circulation efficiency.

\section{LITERATURE REVIEW}

Pearson (1901) proposed the concept of principal component analysis (PCA), which was then extended by Hotelling (1933) to the case of random vectors. Partial least squares (PLS) was first proposed by Wold and Albano (1983), followed by Wold (1989, 1989, 1992) proposing partial leastsquares regression, second-order polynomial partial leastsquares regression, and spline partial least two. Multiplicative regression, Helland (1990) studied the statistical model of the PLS algorithm (mainly PLS1) and found that it is similar to the data interpretation method of the factor analysis method. Qian Daocui (2002) introduced the principle of principal component analysis and the dimensionless processing, mean processing and "logarithmic centralization" of the data processing. Zhang Peng (2004) discussed the principal component analysis comprehensively and compared other 
analysis methods, trying to improve its methods and steps. Meng Bing and Wu Qunying (2007) used data from 17 cities in Shandong Province to study urban performance logistics through principal component analysis. Hong Suzhen (2008) discussed the irrationality of related literature in the comprehensive evaluation of principal components, and put forward the necessary and sufficient conditions for principal component analysis and the index system of evaluation. Chen Baosen (2012) used principal component analysis to analyze the circulation competitiveness of ZA tobacco enterprise, and concluded that market sales and staff quality could affect the tobacco enterprise's circulation competitiveness greatly. Lu Xiaowei and Bi Gongbing (2014) evaluated the efficiency of China's regional cultural industry through principal component analysis and DEA model. The result was that Guangdong and Chongqing were in the rank of effectiveness of cultural industry efficiency, while scale efficiency needs to be increased in Shanghai, Jilin and Xinjiang province and technical efficiency also should be improved in other provinces.

Li Ziling (2006) discussed the problems of partial least squares and structural equation models (PLS-SEM). Furthermore, she improved and validated them by the technology commercialization success index model. He Tao (2006) also discussed the structural equation model and PLS algorithm, focusing on the modeling method and its geometric significance. Zhang Yong (2006) conducted an empirical study on production and purchase of tobacco leaf in China through PLS and structural equation model, and analyzed the influence of relevant factors on the farmer's enthusiasm for tobacco planting. Zhao Fuqiang (2010) studied the customer satisfaction of food companies and auto companies through the PLS algorithm. Lin Sheng (2002) discussed how to use the PLS structural equation model to study customer satisfaction in the service industry and conducted an empirical study in the commercial housing market. Liu Bingsheng et al. (2011) used PLS structural equation model to analyze the data on construction industry in China from 2006 to 2007, and concluded that the three main factors affecting the competitiveness of the local construction industry are regional environment, production factors and industrial organization. Liu Hui (2011) also studied the satisfaction of Chinese higher education students by using the PLS-SEM model. Fei Zhengshun (2012) studied the dynamic optimization method in the framework of PLS, and tried to solve the problem of process dynamic optimization in case of the mechanism model is unavailable.

Chen Ming (2010) studied the competitiveness of circulation industry in 28 cities of China by using factor analysis, and classified and comprehensively examined them according to different indicators. Liu Genrong and $\mathrm{Fu} \mathrm{Yu}$ (2011) studied the regional competitiveness of the circulation industry in 31 provinces of China by using factor analysis, and found that 10 provinces, such as Guangdong, Beijing and Shanghai are competitive. Yang Longzhi (2012) also used factor analysis to study the circulation competitiveness in districts and counties of Wenzhou, and considered that the way to improve the circulation competitiveness is to cultivate "absolute advantages" and eliminate "absolute disadvantages".
Liu Genrong (2014) measured the factors that affecting the circulation industry in 31 provinces of China by using the global principal component analysis method and carried out a comparative study.

In summary, the principal component analysis and partial least squares method have been widely used in empirical research, mainly including the analysis of industry and circulation, but the research on the circulation competitiveness of tobacco companies is very rare. Chen Baosen (2012) [1] only analyzed the influential factors by using the principal component analysis. Due to the characteristics of circulation of tobacco products, principal components analysis can better select the main factors affecting the competitiveness of tobacco enterprises, and PLS can effectively solve the problem of small sample size and multicollinearity. Therefore, based on the actual investigation and statistical yearbook data, this paper combines the two aspects and conducts the study on the circulation competitiveness of China's tobacco enterprises effectively and deeply.

\section{METHODS AND DATA}

The concept of principal component analysis (PCA) was first proposed by Pearson (1901), which explains the internal structure of multiple explanatory variables by using several principal components. However, it requires that the principal components must not be related to each other. Nowadays, software such as SPSS and Stata can carry out principal component analysis. This paper uses Stata12 and the testing methods are kmo, anti and smc. Based on tobacco enterprises and circulation data, Porter's diamond model and the Tobacco Commercial Enterprise Competitiveness Indicator System (Trial), the evaluation indicators which selected in this paper are as follow:

TABLE I. EVALUATION INDEX OF CIRCULATION COMPETITIVENESS OF TOBACCO ENTERPRISES

\begin{tabular}{|c|c|}
\hline Main indicators & Index subdivision \\
\hline Market competition & Per capita sales \\
\hline \multirow{5}{*}{ Capital operation } & Total asset contribution rate \\
\hline & Total labor productivity \\
\hline & Ratio of Profits to Cost \\
\hline & Asset-liability ratio \\
\hline & Single distribution cost \\
\hline \multirow{2}{*}{$\begin{array}{l}\text { Human capital } \\
\text { inves tment }\end{array}$} & $\begin{array}{l}\text { The proportion of investment in } \\
\text { education/technical funding }\end{array}$ \\
\hline & $\begin{array}{l}\text { The proportion of professional and technical } \\
\text { personnel }\end{array}$ \\
\hline Research investment & $\begin{array}{c}\text { R\&D expenses/Research and development } \\
\text { expenses }\end{array}$ \\
\hline Brand awareness & $\begin{array}{l}\text { The proportion of famous brand sales in Chinese } \\
\text { total sales }\end{array}$ \\
\hline
\end{tabular}

Partial Least Squares (PLS) was first proposed by Wold and Albano (1983) to solve the problem of multicollinearity caused by using the least square method. It can effectively solve the problems of multiple collinearity, less sample size and so on. Therefore, it is more applicable to the research on the circulation competitiveness of the tobacco enterprise. In this paper, the above ten indicators and the proportion of foreign tobacco (x11) are used as PLS regression measure variables, introducing the local fiscal revenue, total profit and 
sales as explained variables, so as to study the impact of these factors on the company's own profitability and sales level and measure the degree of competition in the tobacco market and the local government's tax dependence on tobacco. At present, the software that can carry out PLS regression includes SPSS, SIMCA-P, Visual PLS, Minitab and Matlab, etc. This paper uses Visual PLS 1.04b1 and Minitab 16.

The circulation of tobacco is different from the circulation of other commodities. It is regulated by the national monopoly system and easy to be monitored. The flow direction, quantity of flow and velocity of flow are relatively stable, which is a product of the combination of market operation and macro regulation. Yunnan Province is the largest tobacco-producing province in China. And the local government has serious reliance on tax of tobacco. Therefore, this paper mainly uses data of $\mathrm{X}$ tobacco enterprise and some statistical yearbook, especially the data of X tobacco enterprise from 1999 to 2011, China tobacco yearbook, China tobacco industry analysis report and data of related tobacco website. According to the relevant calculations and CPI deflation, the evaluation index data table of X tobacco enterprise in Yunnan Province (19992011 ) is obtained. Then this paper analyzes the data by using Stata12, Visual PLS 1.04b1 and Minitab16.

\section{RESULTS AND DISCUSSION}

First, assume that $\mathrm{x} 1-\mathrm{x} 10$ respectively are per capita sales, total asset contribution rate, total labor productivity, ratio of profits to cost, asset-liability ratio, single distribution cost, the proportion of investment in education/technical funding, proportion of professional and technical personnel, R\&D expenses and the proportion of famous brand sales in Chinese total sales.

Second, according to the principle of Principal Component Analysis (PCA), we standardize the variables (represented by z1-z10), and then get the following table through the PCA command:

TABLE II. THE RESULT OF PRINCIPAL COMPONENT ANALYSIS OF CIRCULATION COMPETITIVENESS

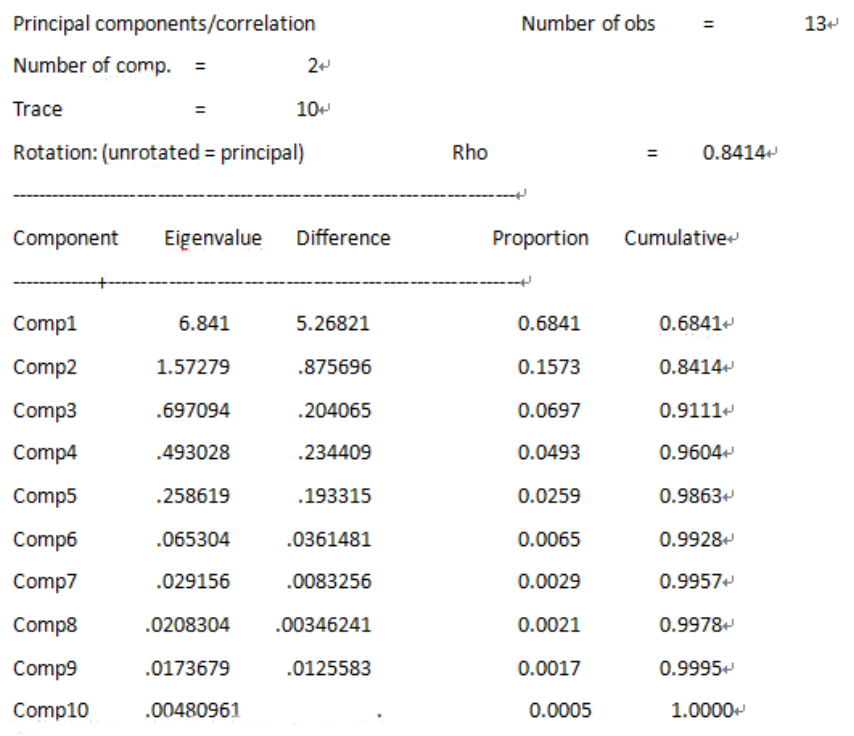

According to the results, it is appropriate to select two principal components, F1 and F2. The kmo (0.767), anti (better), and smc (higher) tests are then performed. And the tests indicate that the data is suitable for principal component analysis.

Finally, we can obtain the following table and finger:

TABLE III. SCORES OF PRINCIPAL COMPONENTS AND TIME SERIES

\begin{tabular}{lcc} 
Comp1 & Comp2 \\
\hline x1 & .9078 & -.02156 \\
x2 & .6184 & .6906 \\
x3 & .8917 & .388 \\
x4 & -.6414 & .369 \\
x5 & .9069 & .06566 \\
x6 & .9328 & -.1293 \\
x7 & -.3533 & .7259 \\
x8 & .9498 & .277 \\
x9 & .9741 & -.1019 \\
x10 & -.8714 & .4168 \\
& &
\end{tabular}

\begin{tabular}{ccc} 
& $F 1$ & $F 2$ \\
\hline 1. & -4.21255 & 2.170443
\end{tabular}

2. -3.594439 .9069415$

3. $-2.206173 \quad 055923$

4. $-2.4335-1.091109$

5. $-1.815117-1.504219$

6. $-.7103205-.6696934$

7. $-.0915176-.8608123$

8. $1.255752-1.345718$

9. $1.610531-.1487029$

10. $2.509305-.0959511$

11. $2.942401 \quad .2724236$

12. $3.172796 \quad .749868$

13. 3.5728331 .560607
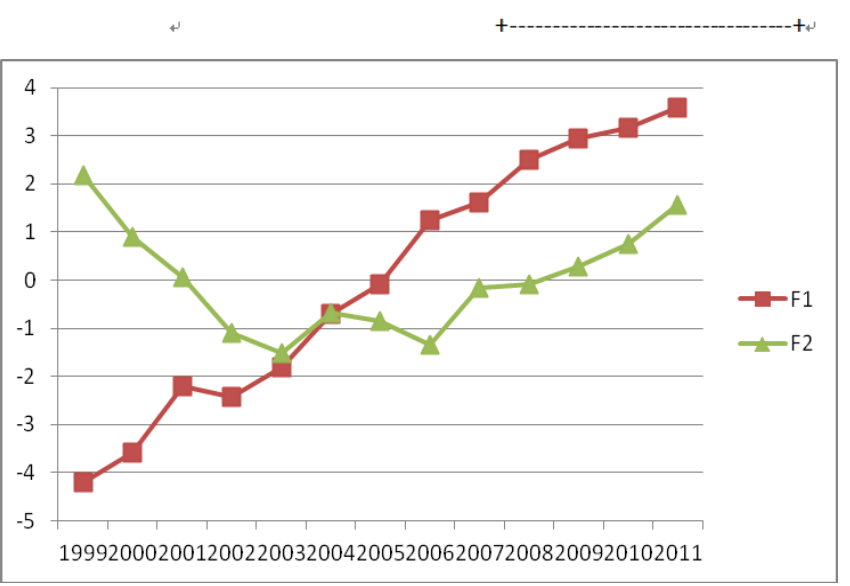

Fig. 1. Changes in time series scores of principal components F1 and F2

As a result, the circulation competitiveness of $\mathrm{X}$ tobacco enterprise shows an upward trend, especially in sales, human capital and R\&D. However, capital structure and other factors make the circulation competitiveness fluctuate dramatically, which indicating that $X$ tobacco enterprise needs to optimize its internal structure. The fluctuation of education funds shows that $\mathrm{X}$ tobacco enterprise does not pay enough attention to staff education and training. In addition, investment in human capital needs to be strengthened.

At the same time, the proportion of foreign tobacco (X11) needs to be introduced as a measure of competition, and then Visual PLS 1.04b1 is adopted as a measurement so that we can get the following finger: 


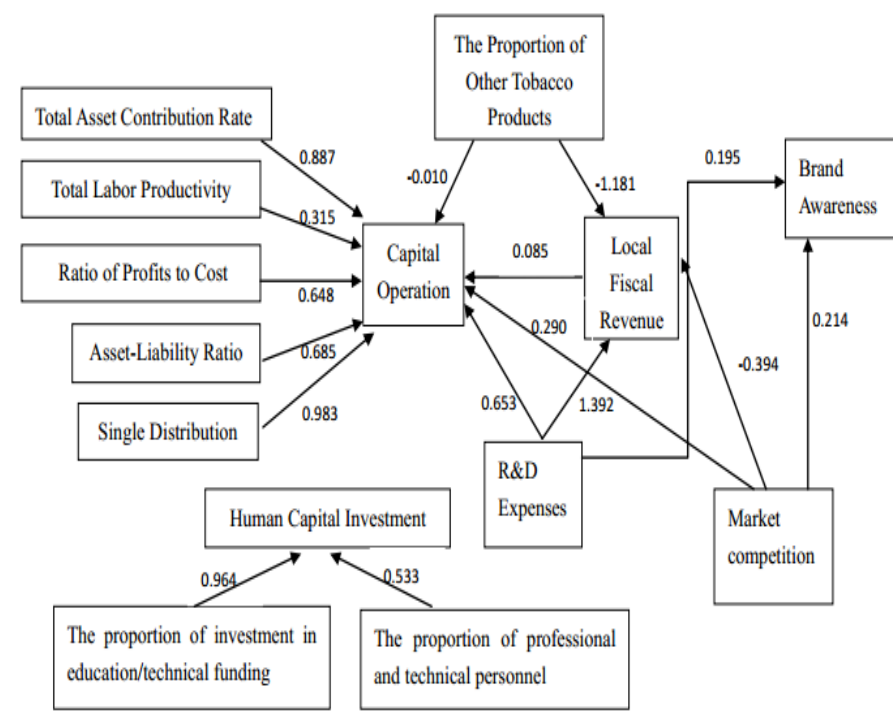

Fig. 2. Measurement of factors influencing the circulation competitiveness of $\mathrm{X}$ tobacco enterprise

From the above finger, we can see that the human capital investment and scientific research can promote the capital operation. Moreover, the scientific research will also increase the brand awareness. The proportion of foreign tobacco has a negative impact on capital operation and local fiscal revenue, which indicates that the natural monopoly exists and the local protectionism takes shape based on the interests of local government. The degree of market competition goes against local fiscal revenue, so the local government becomes a supporter of tobacco monopoly. The total assets contribution rate and single distribution cost have great influence on the internal structure of the tobacco enterprise. Controlling cost and improving efficiency can optimize the internal structure and improve the circulation competitiveness of $\mathrm{X}$ tobacco enterprise. For the human capital of $\mathrm{X}$ tobacco, educational investment can effectively achieve human capital investment, while the proportion of professional and technical personnel is the core of human capital.

Next, this paper uses Minitab 16 to conduct PLS regression. The 11th additional explanatory variable, the proportion of foreign tobacco, aims to measure for the market share to further evaluate if it affects the total amount of profits and taxes, total sales and local fiscal revenue (set as Y1, Y2 and Y3). After the regression, this paper retains the significant variables ( $\mathrm{R}$ above $90 \%$ ), and the results are as follows:

\section{$\mathrm{Y} 1=0.542 \times 1+0.270 \times 2+0.003 \times 4+0.085 \times 7+1.066 \times 9+0.111 \times 10+0.155 \times 11$ \\ $\mathrm{Y} 2=1.662 \times 3+1.356 \times 4+2.449 \times 5+0.287 \times 6+0.841 \times 8+0.079 \times 11$}

\section{$\mathrm{Y} 3=0.296 \times 3+0.097 \times 4+0.069 \times 5+0.219 \times 6+0.423 \times 8+0.269 \times 9$}

It can be seen that the proportion of foreign tobacco has little influence on local fiscal revenue and it also has little effect on the total sales of local tobacco enterprises. This suggests that, to some extent, the local protectionism does existence in tobacco industry and local finance mainly relies on local tobacco enterprises. Therefore, market competition should be introduced by increasing the proportion of foreign tobacco, and the dependence of local governments on local tobacco companies should be reduced to break the local separatist of the tobacco market. Long term consideration needs to be bear in mind by local governments, so that the realization of "Multi-Win" is on the way. According to equation (1), the main factors affecting the total profits and taxes of $X$ tobacco enterprise are the per capita sales, total assets contribution rate, $R \& D$ expenses, the proportion of sales of famous brand in Chinese total sales and the proportion of foreign tobacco, among which the $R \& D$ has the greatest impact. This shows the importance of R\&D to X tobacco. In addition, the proportion of investment in education and technical funding will also have an impact on it, which shows the significance of investing in human capital. According to equation (2), it can be seen that the total sales volume is affected by the total labor productivity, ratio of profits to cost, asset-liability ratio, single distribution cost and the proportion of professional and technical personnel. Therefore, cost control, efficiency improvement and human capital investment are important measures to improve the sales of $\mathrm{X}$ tobacco enterprise. In regard to local fiscal revenue, according to equation (3), it can be known that the influencing factors are mainly the total labor productivity, the single distribution cost, the proportion of professional and technical personnel and R\&D expenses, which indicates that the production and sales of $\mathrm{X}$ tobacco are the sources of increasing local fiscal revenue, and taxation is the leading factor to increase the costs of distribution. To their own consideration, local governments will encourage and support local tobacco enterprises to strengthen scientific research and human capital investment, which, to a certain extent, promotes the development of tobacco enterprises.

\section{Conclusion and Policy Recommendations}

As a pillar industry in Yunnan Province, the tobacco industry has so many famous brands, such as Hongtashan, Yuxi, Honghe and Yunyan. They all have representative scale and product features. Based on local survey data and relevant statistical yearbooks, this paper conducts empirical research on the circulation competitiveness of tobacco enterprises by using principal component analysis and least-squares method, and measures the relevant influencing factors. The study finds that human capital, research and internal structure of capital can improve the circulation competitiveness of tobacco industry. Local governments will support tobacco monopolies and implement local protectionism for their own interests. Therefore, it is necessary to introduce market competition to break the "local separatist" of tobacco, which needs to carry out the reform of tobacco tax and alleviate the local tax dependence. In this way, the circulation competitiveness of tobacco enterprises can be improved, and effective mergers and reorganizations can be implemented to achieve economies of scale. Moreover, market competition will promote the healthy development of tobacco companies and maintain the stability of the tobacco market. According to the above researches, the main policy recommendations are: (1) All industries should focus on human capital investment and $R \& D$, especially in monopolistic industries. Both of them are often overlooked and need to be incorporated into development strategies. (2) Local tax dependence restricts the improvement of the circulation competitiveness of tobacco enterprises, 
which needed tax reforms in China. It can solve local financial dilemmas by setting up a tax return mechanism. (3) The existence of local protectionism has a tremendous negative impact on the circulation competitiveness. It is not conducive to the realization of "Big Circulation" across the country. Therefore, reforms of the evaluation mechanism of the performance of local governments will be needed. Moreover, the local governments should establish a holistic view and the long-term perspective, and adhere to the strategy of sustainable development. (4) The capital structure is an important factor affecting the circulation competitiveness. However, the state-run approach often pays insufficient attention to it and lacks incentives. Therefore, capital structure need to be optimized urgently in various industries of China, especially monopoly industries. Furthermore, the establishment of internal incentive mechanism and supervision mechanism is also required, which will comprehensively improve China's circulation competitiveness. (5) Stronger market forces and strong administrative factors positioned as an important reason for inhibiting the increase of circulation competitiveness, therefore it is of significance to set up supervision institutions and de-administration. Only in this way can we truly play the fundamental role of the market and achieve the organic combination of "Invisible Hand" and
"Visible Hand" which is conducive to the healthy development of China's circulation economy.

\section{REFERENCES}

[1] Chen Baocen, "Tobacco leaf production cost and increase of tobacco farmers' income--An empirical analysis based on Liangshan Prefecture and Fuxin City," Doctoral thesis of Sichuan Agricultural University, pp. 114-123, 2012(3).

[2] LI Ziling, "Research on Structural Equation Model Structure and PLS Algorithm,” Master's thesis of Wuhan University of Technology, pp. 16-23, 2006(11).

[3] Liu Genrong and Fu Yu, "Evaluation of Regional Competitiveness of China's Circulation Industry-Based on Factor Analysis,” Business Economics and Management, pp. 11-18, 2011(01).

[4] Zhang Yong, "Research on Tobacco Purchase Price in China,” Doctoral thesis of University of Science and Technology of China, pp. 35-57, 2006(4).

[5] Inge S. Helland, "Partial Least Squares Regression and Statistical Models,” Scandinavian Journal of Statistics, pp. 97-114, 1990.

[6] Wold, H, "Soft modeling-The basic design and some extensions," Systems Under Indirect Observation II [J]. North-Holland Press. Amsterdam. The Netherlands, pp. 1-53, 1982.

[7] Wold, S., Geladi, P, Espensen, K. \& Ohman, J, "Multi-way principal components and PLS analysis,” Chemometrics 1, pp. 41-56, 1987. 